\title{
The Study on Students' Vocabulary Size
}

\author{
YULIANA T WERO \\ Universitas Negeri Gorontalo \\ yulianawero18@gmail.com \\ Prof. KARMILA MACHMUD, S.Pd, M.A, Ph.D \\ Universitas Negeri Gorontalo \\ karmila.machmud@ung.ac.id \\ NURLAILA HUSAIN, SS, M.Pd \\ Universitas Negeri Gorontalo \\ nurlailahusain@ung.ac.id
}

\begin{abstract}
This study intends to know the vocabulary size of English Department Students in the eighth semester. The population included all students in the English Department, specifically in the eighth semester (Class of 2013, Academic Year 2016/2017). A purposive sampling method was used in taking the samples, and there were 21 students as the sample obtained from 122 students as the population. The method of this research was a quantitative method. The instruments used in collecting the data were tests, divided into two: Receptive Vocabulary Size Test (RVST) and Productive Vocabulary Size Test (PVST). In analyzing the data, a numerical descriptive statistic was utilized. The results show that students' receptive and productive vocabulary size were 3,110 words and 1,841 words respectively or in general around 4,905 words, with the receptive vocabulary knowledge was higher than productive vocabulary knowledge. However, it shows a lower result for the students who learned English for about eight semesters, which is it should be more than that. Therefore, from this point the lecturers can utilize the test of vocabulary to observe their students' strengths and weaknesses in language uses.
\end{abstract}

Keywords: vocabulary size; vocabulary level test; receptive vocabulary; productive vocabulary

\section{INTRODUCTION}

Practicing and learning English skills such as speaking, listening, writing and reading as the most basic of language skills are really needed. Moreover, to have a good skill in English, vocabulary mastery is the most important for anyone to learn. A foreign language learner, based on Ali (2010), "can speak fluently and accurately, write easily or understand what they read and hear if they have adequate vocabulary and ability to use it accurately". In a wide variety of language skills, students with rich vocabulary are more proficient than students with less vocabulary (Meara, 1996, as cited in Astan \& Tamah, 2015).

In addition, Nation as cited in Putra (2009) shows the data about the learning times of Japanese and Indonesian students who learn English for about "five hours a week, for about 40 weeks a year, for about five years or very approximately 1,000 hours". According to these learning times, Barnard (1961) and Quin (1968) as cited in Putra (2009) have the result of their 
study which shows that the vocabulary size of Indian and Indonesian learners are less than 2000 words in general.

Then, in 1999 Nurweni and Read's study shows that only 1226 words that could be understood by the first year students of Lampung University. However, the study of Suteja (2007) shows that students in grade 10 from National Plus School Indonesia could even have the vocabulary size around 5000 words. It is happened because all of their subjects are taught in English. According to Putra (2009), "the size can actually increase to a great extent if there is more English exposure during the school time or if the school adapt international curriculum". It is proved that the more they learn English the more vocabulary size they have. Based on these figure, it makes the researcher in this study are more curious about the vocabulary size of EFL learners in university level nowadays, since vocabulary mastery becomes the crucial things in language used. Qian (2002) as cited in Astan and Tamah (2015) states that vocabulary size is sometimes called as vocabulary breadth that refers to the number of words that students' know. Therefore, the researcher wants to measure students' vocabulary size that takes place in the Faculty of Letters and Culture in Universitas Negeri Gorontalo, specifically at the English Department.

The participants in this study were English Department students in the eighth semester. They were recruited based on some requirements, such as the students have passed all productive and receptive skills (speaking, listening, writing, reading) with 3 marks or B (standard passing grade), since the tests used are to measure their receptive and productive knowledge, which means the students also should have a good knowledge in that subject, proved by their transcript that clarify they passed the subjects. Another requirement in recruiting the sample was that students had passed Research on Language and Seminar on Language subjects with the same standard passing grade, because one of the words frequency level are measure their academic vocabulary, so it is believed that while learning this subjects students could increase their academic vocabulary knowledge, because they need to conduct a research that force them to read more academic text.

\section{THEORETICAL FRAMEWORK VOCABULARY KNOWLEDGE}

In learning English, the most important things that should be mastered by the students are vocabulary. According to Milton and Daller (2013), vocabulary knowledge has an important role in a language, without vocabulary there would be no language production or comprehension. If the student's lack of vocabulary, they will be difficult in using English because they cannot understand others, even express their own idea. Wilkins (1972) as cited in Alfaki (2014) stated that very little can be communicated without grammar, but nothing can be conveyed without vocabulary. In addition, Richards (2002, p.255) stated that "vocabulary is the main component of language proficiency and the basic for how well learners can speak, write, read, and listen". From these opinions, shows that how vocabulary can affect to the four skills that are really needed in language learning, and to master those skills, vocabulary must be mastered first.

Moreover, according to Nation \& Waring (1997) as cited in Hajiyeva (2015) vocabulary knowledge allows language use, language use allows vocabulary knowledge to be increased, and word knowledge allows vocabulary knowledge and use of language to be increased. In addition, Read (1997) as cited in Hajiyeva (2015) stated that it is important to evaluate the knowledge of the words of learners if vocabulary knowledge is accepted as a fundamental component of foreign or second language (EFL or ESL). From those explanations, it is proved that knowledge 
of vocabulary is really needed in order to have a good language proficiency in language use. Therefore, it's really important to measure the size of students' vocabulary in order to know their vocabulary learning.

\section{RECEPTIVE ND PRODUCTIVE VOCABULARY KNOWLEDGE}

There are two types of vocabulary, according to Nation (2001). They are receptive and productive vocabulary. Receptive vocabulary refers to the words that recognized and understood by native speakers and foreign learners but hardly ever used, it is used passively in either listening or reading. While in speaking and writing, productive vocabulary is actively used. Similarly, Zhou (2010, p.15) stated that "receptive and productive vocabulary comprehension is a very important dimension of vocabulary awareness". Receptive vocabulary knowledge refers to the capacity to comprehend a word when it is heard or seen, whereas productive knowledge is the ability to generate a word when it is written or spoken. "It is usually believed that receptive knowledge are known first and after deliberate studied become available for productive use" (Zhou, 2010, p.15). Therefore, vocabulary knowledge should be regarded as a continuum on which a word grows from receptive to productive status. It is proved by some result of study about vocabulary size that shows students' receptive vocabulary size is much larger than their productive vocabulary size.

For that reasons, it shows how importance vocabulary for language proficiency because four skills in English can be mastered if we mastered receptive and productive vocabulary that cover the ability of listening, reading, speaking, and writing. Based on Saville-Troike (1984) and Laufer (1997) as cited in Laufer et. al. (2004) vocabulary size is related to success in reading, writing, and general language proficiency as well as to academic achievement.

\section{VOCABULARY SIZE OF EFL LEARNERS}

Vocabulary size refers as vocabulary breadth by Qian (2002) as cited in Astan and Tamah (2015). It refers to the number of words that a learner knows, at least the surface meaning. Furthermore, Nation (2001) as cited in Nemati (2010, p.46) stated that "the size of vocabulary has been taken to refer to the sum or number of words that students know at a given level of language proficiency". In addition, Meara (1996) as cited in Astan and Tamah (2015) indicates that the fundamental dimension of lexical competence is size, and also students with large vocabulary skills are more proficient in a wide range of language skills than students with smaller vocabulary skills.

Vocabulary plays an important role in foreign language learning. The development of rich vocabulary is important when learners acquire English as a foreign language. Moreover, according to Nation (1994) as stated in Chujo (2004, p.231) "a rich vocabulary makes the skills of listening, speaking, reading, and writing easier to practice". It can be concluded that the size of vocabulary is really determining in terms of proficiency in language used, especially for learner that learn English as a foreign language.

In addition, as cited in Putra (2009), here are some data about vocabulary size of EFL university students', which collected from several studies include the data of his study in order to make a comparison about the development of students' vocabulary size from year to year. 
TABLE 1. Vocabulary size of EFL university students

\begin{tabular}{ccl}
\hline Author & Subjects & Vocabulary Size \\
\hline Barnard (1961); Quinn (1968) & Indonesian and Indian & Less than 2,000 words \\
Lin (1992) & Taiwanese & R: less than 2,000 words \\
Laufer (1998) & Israel & R: 1,900 - 3,500 words; \\
& & P: 1,700 - 2,550 words \\
Barrow, Nakanishi, Ishino(1999) & Japanese & 2,304 words \\
Nurweni and Read (1999) & Indonesian & 1226 words \\
Chen (1999) & Taiwanese & P: less than 2,000 words \\
Huang (2004) & Taiwanese & R: 2,838 words \\
Suteja (2007) & Indonesian & R: around 5,000 words \\
Putra (2009) & Indonesian & $\begin{array}{l}\text { R: around 5.388 words } \\
\text { P: around 3500 words }\end{array}$ \\
\hline
\end{tabular}

Source : Putra (2009)

Note: $\mathrm{R}$ = receptive vocabulary; $\mathrm{P}=$ productive vocabulary.

When there is no R or P label, then it refers to the vocabulary size in general

\section{VOCABULARY LEVEL TEST}

RECEPTIVE VOCABULARY SIZE TEST (RVST) AND PRODUCTIVE VOCABULARY SIZE TEST (PVST)

Read (2000) as cited in Eyckmans (2004) to measure vocabulary size in a valid and reliable way, vocabulary size tests must consist of many items, such as non-time-consuming administration procedure, which means that the test task has to be fairly simple. One of the most famous vocabulary tests that covered these discrete is Nation's vocabulary Levels Test. This test called as "the nearest thing to a standardized vocabulary test currently available" based on Meara (1996) as cited in Kremmel and Schmitt (2017).

Vocabulary Level Test originally design by Paul Nation in the 1980s and published in 1990, then in 1993 it was first developed and validated by Norbert Schmitt (schimtt, schimtt, \& Clapham, 2001). This test is for measure the written receptive vocabulary size that defines "as the number of words that are partially recognized when the meaning sense of the target words is given" (Anderson \& Freebody 1981, as stated in Putra 2009). This Receptive Vocabulary Size Test (RVST) is divided into four separate sections of frequency levels: 2000, 3000, 5000 words frequency level, also include Academic Word List (AWL) for learner in academic context. Here is an example of Receptive Vocabulary Size Test:

1 business

2 clock

3 horse

$6 \quad$ part of a house

4 pencil

3 animal with four legs

5 shoe

$4 \quad$ something used for writing

6 wall 
In this test the learners have to match three of the six words in the left with the correct meaning in the right. The test has 30 items for each level, means for four words frequency level it will be 120 items for the totality. All the words that used in this test are the representative of all the words in each level.

Besides that, according to Zimmerman (2004), Laufer and Nation was modified the version of Vocabulary level test become Productive Vocabulary Level Test (PVLT). Putra (2009), this test created to "measure a controlled productive ability". Moreover, according to Laufer (1998) as cited in Zimmerman (2004), productive vocabulary divides into Controlled Production and free production. Controlled production means that the ability of students to produce words when the teacher or test required them to do so. While free production is the ability of students to produce the words when they write and speak.

Laufer and Nation (1999) as cited in Zimmerman (2004) stated that "The Productive Vocabulary Level Test is a very practical instrument", the result easy to score, and the test does not take long to complete. In addition, by giving the first letter as the cue, it requires students to produce words rather than to simply recognize them (Zimmerman, 2004). Here are some examples of the test.

1. I'm glad we had this opp to talk. [Answer = opportunity]

2. The rich man died and left all his we

3. Ann intro to his son.

There are 18 items that represented each level. Means that, there are 72 items on the tests as the total of four frequency level. Similar to receptive vocabulary size test, this test also divided into four frequency levels: 2000, 3000, 5000, and University Word Level (UWL). The difference of this frequency level is the Receptive Vocabulary Size Test (RVST) using Academic Word Level (AWL), while Productive Vocabulary Size Test (PVST) using University Word Level (UWL).

\section{WORDS FREQUENCY LEVEL}

According to Senturk (2016), vocabulary size test is intended to provide an estimate of vocabulary size in general or academic English and it is shown that vocabulary size is directly related to the ability to use English in different ways based on the function of the test. That is the reason of employing the frequency level in the test, since the levels of the test represent different word frequencies also has the utility to measure students' ability in vocabulary knowledge in each level of word.

Such as in 2000-word level, this is the first level that contains high frequency words of General Service List compiled by West in 1953 (Cameron, 2002). This level contain the knowledge of the most frequent 2000 words in English that provides the bulks of the lexical resources needed for basic daily oral communication (Senturk, 2016). The further levels, 3000 word level, and 5000 word level contain each 1000 words as the third and the fifth most frequent word in English from a list compiled by Thorndike and Lorge in 1944 (Cameron, 2002).

According to Senturk (2016), the representative word in 3000 word level provides additional material for spoken discourse, and the knowledge in this word is the threshold which should allow learners to begin to read authentic text. In addition, the knowledge of 5000 words level should allow learners to infer the meaning of many of the novel words from context, and to understand most of the communicative content of the text.

Furthermore, this test also measure students' ability in academic word knowledge, therefore there are Academic Word Level (AWL) and University Word Level (UWL) that used. AWL is 
used in receptive test, while UWL is used in productive test. These two levels of academic words are not included in the general service list, but often occur across a wide range of academic texts.

The differences are the university word level consist of 836 words from university word list by Xue and Nation in 1984, and its covers $9.8 \%$ of the 3.5 million word corpus of academic text. While academic word level consist of 570 words from academic word list by Coxhead in 2000, although the number of words are smaller than university word list, but its cover $10 \%$ of the corpus (Zhou, 2010). Therefore, the AWL provides a wider coverage of academic texts than the UWL.

\section{THE IMPORTANCE OF VOCABULARY SIZE TEST}

According to Daller, Milton, \& Treffers-Daller (2007) as cited in Mochizuki (2012, p. 44), "size or breadth are the first dimension of vocabulary knowledge". Vocabulary test can be used to helps students to place in proper class level (placement test), and by measure's their vocabulary size, it is believed can give indication for overall of their language proficiency (Schmitt, 1994). It also means by giving vocabulary test it can motivate students to study, because it can show them about their progress in learning new words.

Originally design as a diagnostic tool for teachers, it has proven that Vocabulary level test useful in helping teacher determine the kind of attention they should give for the specific groups of learners to learn vocabulary (Laufer and Nation, 1999). Therefore, the utilizing of Vocabulary level test is suitable to measure students' vocabulary size, since it can be useful for the teacher and the students itself.

\section{METHOD}

A quantitative method was used in this research. According to Sukamolson (2007), quantitative research is the numerical interpretation and handling of observations with the intention of describing and providing an explanation of phenomena that those observation display. In order to measure how large students' vocabulary size, this study used descriptive statistic, also the calculation that lifted from the previous study to estimate the vocabulary size.

\section{POPULATION AND SAMPLE}

The population in this research was the students of English Department, Class of 2013 of Faculty Letters and Culture, Universitas Negeri Gorontalo. In this research, the writer used a purposive sampling technique in the process of choosing sample. The purposive sampling was used because of several aspects that necessary in taking the sample, such as the students had passed all productive and receptive skills (speaking, listening, writing, reading) with 3 marks or B (standard passing grade), since the tests used were to measure their receptive and productive knowledge, which means the students also should have a good knowledge in that subject, proved by their transcript that clarify they passed the subjects.

Another requirement in choosing the sample was students had passed Research on Language and Seminar on Language subjects with the same standard passing grade, because one of the words frequency level are measure their academic vocabulary, so it is believed that while learning this subjects students could increase their academic vocabulary knowledge, since they need to conduct a research that force them to read more academic text. To find out whether the students were eligible to be the sample in this study, the researcher checked one by one their 
grade transcripts to filter the population into the sample that the researcher need to participate in this study. Based on those requirements, the researcher found 21 students from 122 as the total of population.

\section{DATA COLLECTION AND ANALYSIS}

The data of this research were obtained from the students' scores of both vocabulary size tests (receptive and productive). In order to collect the data, tests were used as the instruments. The tests focused on vocabulary testing. In order to measure how large students' vocabulary size, this study used numerical descriptive statistic, where the first step was to describe about the result of students' vocabulary mastery by determining the mean, the minimum and maximum score, and the standard deviation. Then, calculating the estimated of students' vocabulary size was done. Here are the following formulas:

Mean score:

$$
\begin{aligned}
\bar{x}=\frac{\sum x_{i}}{\frac{n}{x}} & =\text { the mean score of data set } \\
\sum x_{i} & =\text { the sum of scores } \\
n & =\text { number of scores }
\end{aligned}
$$

\section{Standard Deviation:}

$$
\begin{aligned}
& \mathbf{S}=\frac{\sqrt{\sum(x-\bar{x}) 2}}{n-1} \\
& x=\text { value in the data set } \\
& \sum x=\text { sum of value } \\
& \bar{x}=\text { mean of the data set } \\
& \mathrm{n}=\text { number of data point }
\end{aligned}
$$

\% Mastery: percentage of the average (mean) vocabulary mastery.

To get how many percentages of vocabulary size of students in each frequency, the researcher used the formulas by Putra (2009):

$$
\begin{gathered}
\frac{x}{N} \quad \mathrm{x} 100 \\
\bar{x}=\text { the mean score } \\
N=\text { number of items }
\end{gathered}
$$


After getting all the result above, the researcher estimate the vocabulary size by using calculation that still adopt from Putra (2009), and then show the estimated vocabulary size into the table. Here is the following calculation for estimated vocabulary size:

(Number of representative words for each word frequency $X \%$ Mastery)

For example: 2000word level $(2000 \times 95 \%)=1900$ words

\section{FINDINGS AND DISCUSSION FINDINGS}

STUDENTS' VOCABULARY MASTERY

The students' vocabulary mastery can be determined by calculating the number of correct responses in each vocabulary levels test. Receptive Vocabulary Size Test consists of four word frequency level with 30 items in each frequency, means there are 120 items for the entirety. Each item give 1 point with correct answer, and 0 for wrong answer. While for Productive Vocabulary Size Test, the numbers of test for each frequency are 18, and it will be 72 for the total of four frequencies.

Answers are considered correct or given 1 point if students write the correct word and part of speech, if they make a mistake in spelling and grammar, for instance, the deal answer is opportunity, but they answered opportunities it will be considered correct since vocabulary are being tested, but with the point is 0.5 because it is not the real expected answer, and for the wrong answer they will get 0 . By using a numerical descriptive statistic method, here are the first steps of analyzing the data to describe about the results of students' vocabulary mastery. It is shown in the Table 2 below.

TABLE 2. Vocabulary mastery descriptive statistic

\begin{tabular}{ccccccc}
\hline & $\begin{array}{c}\text { N } \\
\text { items }\end{array}$ & Min & Max & Mean & \% & $\begin{array}{c}\text { Standar } \\
\text { Deviation }\end{array}$ \\
& & & & & & \\
\hline R-VST- 2000 word level & 30 & 15 & 30 & 23.904 & $\mathbf{7 9 . 6 8 1}$ & 7.948 \\
$\mathbf{3 0 0 0}$ word level & 30 & 5 & 30 & 18 & $\mathbf{6 0}$ & 7.122 \\
$\mathbf{5 0 0 0}$ word level & 30 & 0 & 26 & 15.857 & $\mathbf{5 2 . 8 5 7}$ & 7.124 \\
Academic word level & 30 & 0 & 28 & 20.523 & $\mathbf{6 8 . 4 1 1}$ & 2.991 \\
\hline P- VST- 2000 word level & 18 & 5 & 15 & 9.547 & $\mathbf{5 3 . 0 3 9}$ & 3.188 \\
$\mathbf{3 0 0 0}$ word level & 18 & 0 & 13 & 4.738 & $\mathbf{2 6 . 3 2 3}$ & 3.654 \\
$\mathbf{5 0 0 0}$ word level & 18 & 0 & 16 & 4.928 & $\mathbf{2 7 . 3 7 8}$ & 3.760 \\
\hline University word level & 18 & 0 & 16 & 5.261 & $\mathbf{2 9 . 2 2 8}$ & \\
\hline
\end{tabular}

The result of test done by 21 students as the samples is explained in the table above. By looking at each row in Table 2, we can see the varying score of students' test result in each frequency level of both of the test. From the percentage of each average score, it seems that 
students' vocabulary mastery in receptive vocabulary test was higher than productive vocabulary test. The students could reach $52 \%$ - $79 \%$ mastery in receptive vocabulary test, while for productive vocabulary test they only cover about $53 \%$ of the 2000 word level and struggled at 3000,5000 , and UWL word level (26\% - 29\% mastery).

\section{STUDENTS' VOCABULARY SIZE}

Having finished doing the first step of analyzing students' vocabulary mastery, the second steps focuses on how large the students' vocabulary size is, which is at the same time, it is also can answer the research question of this study. The size of vocabulary itself can be estimated based on the students' result of vocabulary mastery, by using the following calculation:

(Number of representative words for each frequency $\mathrm{x} \%$ mastery)

For example, the size of 2000 word level: $(\underline{2000} \times \underline{95 \%})=1900$ words

The following tables show the estimated vocabulary size of English Department students in eight semesters at Universitas Negeri Gorontalo, which is calculated based on the above principles.

TABLE 3. Receptive Vocabulary Size of English Department students in eight semesters at Universitas Negeri Gorontalo

\begin{tabular}{cccc}
\hline & \% Mastery & Number of representative & RVS per word \\
& & Words & level \\
\hline R-VST- 2000 word level & 79.681 & 2000 & 1593 \\
3000 word level & 60 & 1000 & 600 \\
5000 word level & 52.857 & 1000 & 528 \\
Academic word level & 68.411 & 570 & 389 \\
Total & & $\mathbf{4 5 7 0}$ & $\mathbf{3 1 1 0}$ \\
\hline
\end{tabular}

After being calculated, the result of Receptive Vocabulary size has shown in table 2. The 2000 word level got the highest level of proficiency with 1593 vocabulary size out of 2000 words as the representative; while for 3000 and 5000 word level got the lower result, with 600 and 528 words for each level out of 1000 words as the representative. This makes the Academy word list as the second highest result after 2000 word level, with 389 words out of 570 as the representative word in Academy word list.

TABLE 4. Productive Vocabulary Size of English Department students in eight semesters at Universitas Negeri Gorontalo

\begin{tabular}{cccc}
\hline & \% Mastery & $\begin{array}{c}\text { Number of representative } \\
\text { Words }\end{array}$ & $\begin{array}{c}\text { RVS per word } \\
\text { level }\end{array}$ \\
\hline P-VST- 2000 word level & 53.039 & 2000 & 1061 \\
3000 word level & 26.323 & 1000 & 263 \\
5000 word level & 27.378 & 1000 & 273 \\
University word level & 29.228 & 836 & 244 \\
Total & & $\mathbf{4 8 3 6}$ & $\mathbf{1 8 4 1}$ \\
\hline
\end{tabular}


Similar to the result of vocabulary size, the result of proficiency level of Productive Vocabulary size shown that, students had a better performance in 2000 word level with 1061 words, and the second highest level is university word level with 244 words out of 836 as the representative words in university word list. Lastly, the lower result shown by 3000 and 5000 word level, with each vocabulary size 263 and 273 words.

Statistical analysis was done on the scores, and from table 2 and 3, it is estimated that students' vocabulary size are 3,110 words in receptive and 1,841 words in productive, or in general around 4,951 words. It is also showed that, the participants have relatively high score on 2000 word level, which indicates that students know most of the lexical tools needed for simple daily oral communication. The second highest result is from academic/university word level, showing that they have the information required to identify the academic terms that often appear in a wide spectrum of academic text.

The moderate result come from 3000 word level, which means that the students have gained additional content for spoken discourse, and the last one, a relatively low level in 5000 word level. While many terms at this point are still unknown, the learners could infer from the context the significance of many of the novel's word and understand much of the text's communicative material.

The result of this vocabulary size also indicates that the Receptive Vocabulary Size (RVS) is higher than Productive Vocabulary Size, this happened as well in some research before in the same field, where the students know more vocabulary receptively than they do productively. According to Zhou (2010), the development of productive knowledge far behind of receptive knowledge because for the earliest learning, students often to be able to recognize a word by its form and understand what it means. Then gradually, with more practice of this word in reading, listening, writing, or some other activities, learners increase their knowledge of this word and learn to use the word productively in writing or speaking. Therefore, obviously that productive vocabulary knowledge builds on receptive knowledge.

\section{DISCUSSION}

It was found that the students' receptive and productive vocabulary size were 3,110 words and 1,841 words respectively or in general around 4,905 words, while according to Nation (Learning, p.15) as cited in Putra (2009) stated that "students with receptive knowledge of 5,000 words can read approximately $88.6 \%$ - 89.4\% of general and academic texts". In additional, "with 2,000 words of productive vocabulary size is more than enough to be functional in writing and speaking activities for EFL students who has studied English for approximately five years" (Nation, p.177, as cited in Putra, 2009).

Since the students that became the sample in this study were them in eight semesters or in the last year of their study, it means that they learned English for almost 4 years, coupled with their learning experience in junior and senior high school about English subjects, and since almost all the subjects in English Department are taught in English, it is supposed that students have rich of vocabulary. With this learning experience, we can assume that students in present study were learning English for approximately five years similar to Nations' statement. However, the result that was found in this study shows the less number of words receptively and productively compare to the Nations'. There is big range especially for Receptive vocabulary size; it is about 1,910 words, while for Productive vocabulary size only 185 words. 
Nevertheless, it is adequately satisfied, because the result of the present study was higher than what the other researcher found before, such as in 1999, Indonesian university students' vocabulary size was found to be around 1,266 words. On the other hand, the recent research from Suteja and Putra still shows the high number compare to this study. Suteja (2007) as cited in Putra (2009) found that the high school students in grade 10 from a National plus school (The schools that claimed have more in-class English exposure as most of the subjects are taught in English) in Indonesia could even have vocabulary size almost 5,000 words receptively. Furthermore, the result from Putra (2009) shows that the English laboratory students who took Reading skills course from the International Program of Food Technology department (27 students) and International Relation department (5 students) at Universitas Pelita Harapan, could reach around 5,388 words for receptive vocabulary size, and around 3,500 words for productive vocabulary size. Even so, the present study and the earlier studies indicate the consistent result, which assert that receptive knowledge is usually higher than productive knowledge.

In addition, although these numbers measures from the average score of students that become the sample to represent the totality of students, the result of each individual also really important since the result of their test will determine the whole result in the end. Therefore, these results actually not really measure the ability of vocabulary knowledge of each individual, since the result was accumulated with the others. Similarly, when looking at the individual measure levels in the present study $(2 \mathrm{~K}, 3 \mathrm{~K}, 5 \mathrm{~K}, \mathrm{AWL} / \mathrm{UWL})$, a large variation exists. For example, in the 5K level Receptive Vocabulary Size Test (RVST), their scores ranged from 0 to 26 (out of 30), while for 5K level Productive Vocabulary Size Test (PVST) the ranged from 0 to 16 (out of 18 ), which reflects a serious vocabulary challenge.

The results of vocabulary size in the present study were found from the average score of 21 students that represent all the population, means that the test result of each individual is not really measure their vocabulary size, but assessed as the whole. Consequently, even the some students has a high score in their test while the others has a low score, it will be influential for the final result. The vocabulary size can be high or even low averagely, depends on how much students answer the test correctly. Therefore, it is possible that the sufficient result of students' vocabulary size caused by thing that related to the students' background and students' vocabulary knowledge.

\section{CONCLUSION AND SUGGESTIONS CONCLUSION}

As can be seen from the results, it can be concluded that vocabulary as a component of every language, in communication, reading text, and other aspect of language learning are really important. Estimating the vocabulary size has been interesting for the researcher to measure the students of English Department who learned English as foreign language. This study examined the Receptive vocabulary size and Productive vocabulary size of English language with each level of proficiency. Based on the result of analyzing the data, in the 5000 and 3000 word level, the students' performance seems not as good as it does in the 2000 word level. Then, for Academic word level and University word level, the students had a better result after 2000 word level.

The result about level of proficiency was the same among Receptive vocabulary size and Productive vocabulary size, but the result of students' vocabulary size has been shown that the Receptive vocabulary size with 3110 words out of 4570 word as the representative was higher than Productive vocabulary size with only 1841 words out of 4836 representative words. It was 
also found that not all words that are recognized or receptively known, can be completely recall or productively known, when they answer the test. For that reason, students' productive vocabulary got the lower result.

\section{SUGGESTIONS}

For students in university, learning vocabulary is something that is done while receiving the material from the lecturer, or reading some academic text when they found the meaning in a context. Therefore, in achieving the students' success in learning English, the lecturer should make sure that they teach as many related vocabulary items, whether for basic communication skill or for any academic purposes. Since the students' receptive vocabulary size is higher than productive vocabulary size, it means that the lecturers also should make sure that, when they are teaching more vocabulary items, the students are learning them more deeply by giving them more practices, such as giving the assignment that related with some reading materials from different academic disciplines or any other practices to perform their ability in producing word that appropriate with the grammatical pattern, or something else that makes the students increasing their vocabulary memory, because the more they practice, the chance to learn new word from different word level are bigger.

\section{REFERENCES}

Ali, I. R. (2010). The correlation between students' vocabulary mastery and reading comprehension. Jakarta: State Islamic University Syarif Hidayatullah.

AlfAki, I. M. (2014). Vocabulary input in English language teaching : Assesing the vocabulary load in spine five. International journal of English language and linguistics research, 3, 1-14. Retrieved from https://www.researchgate.net/publication/276273385_Vocabulary_Input_in_English_Language_Teaching _Assessing the Vocabulary_Load_in_Spine_Five .

Astan, C., Tamah, S. M. (2015). The correlation between vocabulary size and the reading comprehension of the english education department student. Surabaya: Universitas Katolik Widya Mandala Surabaya.

Cameron, L. (2002). Measuring vocabulary size in English as an additional language. Language Teaching Research, 6,2, 145-173. doi: 10.1191/1362168802lr103oa.

Chujo, K. (2004). Measuring vocabulary levels of English textbooks and tests using a BNC lemmatised high frequency word list. Language and Computers, 51, 231-249 Retrieved from https://www.researchgate.net/publication/233486890_Measuring_Vocabulary_Levels of English_Textboo ks_and_Tests_Using_a_BNC_Lemmatised_High_Frequency_Word_List.

Eyckmanas, J. (2004). Measuring receptive vocabulary size. Netherland: LOT

Hajiyeva, K. (2015). Exploring the relationship between receptive and productive vocabulary sizes and their increased use by azerbaijani english majors. Antwerpen, Belgium: Canadian Center of Science and Education.

Kremmel, B., Schmitt, N. (2017). Vocabulary level test. The TESOL Encyclopedia of English Language Teaching (eds J.I. Liontas, T. International Association and M. DelliCarpini). doi: 10.1002/9781118784235.eelt0499

Laufer, B., Elder, C., Hill, K., Congdon, P. (2004). Size and strength: do we need both to measure vocabulary knowledge?. Language Testing, 21(2), 202-206. doi: 10.1191/0265532204lt277oa.

Laufer, B., Nation, P. (1999). A vocabulary-size test of controlled productive ability. Language Testing, 16(1), 3351. doi: 10.1177/026553229901600103.

Milton, J., Daller, J. T. (2013). Vocabulary size revisited: the link between vocabulary size and academic achievement. Applied Linguistics Review, 4 (1), 151-172. doi: https://doi.org/10.1515/applirev-2013-0007,

Mochizuki, M. (2012). Four empirical vocabulary test studies in the three dimensional framework. Vocabulary Learning and Instruction, 1(1), 44-52. doi:http://dx.doi.org/10.7820/vli.v01.1.mochizuki. 
Nation, P. (2001). Learning vocabulary in another language. United Kingdom: Press Syndicate of The University Of Cambridge.

Nation, P. (2004). What do you need to know to learn a foreign language?. New Zealand: Victoria University of Wellington.

Nemati, A. (2010). Proficiency and size of receptive vocabulary: comparing efl and esl environments. International Journal of Education Research and Technology, 1(1), 46-53. Retrivied from http://www.soeagra.com.

Putra, Y. (2009). The relationship between vocabulary size and writing ability of the English language laboratory students at universitas pelita harapan. Thesis. Karawaci: Universitas Pelita Harapan,

Schmitt, N. (1994). Vocabulary testing : questions for test development with six examples of tests of vocabulary size and depth. Japan : Minatogawa Women's College.

Schmitt, N., Schmitt, D., Clapham, C. (2001). Vocabulary levels test developing and exploring the behaviour of two new versions of the vocabulary test. Language Testing, 18(1), 55-88. doi: $10.1177 / 026553220101800103$.

Şenturk, B. (2016). Self-regulation Strategies and Vocabulary Size of EFL Turkish University Students. Procedia Social and Behavioral Sciences, 232, 90-97. doi: 10.1016/j.sbspro.2016.10.023.

Sukamolson, S. (2007). Fundamentals of quantitative research. Bangkok: Chulalongkorn University.

Zhou, S. (2010). Comparing receptive and productive academic vocabulary knowledge of chinese efl learners. Asian Social Science, 60, 14-19. Retrieved from www.ccsenet.org/ass.

Zimmerman, K. J. (2004). The role of vocabulary size in assessing second language proficiency. Provo: Brigham Young University. 